\title{
Structural Changes Underlying Compensatory Increase of Diffusing Capacity after Left Pneumonectomy in Adult Dogs
}

\author{
C. C. W. Hsia, ${ }^{\star}$ F. Fryder-Doffey, ${ }^{\star}$ V. Stalder-Navarro, ${ }^{\star}$ R. L. Johnson, Jr., ${ }^{\star}$ R. C. Reynolds, “ and E. R. Weibel ${ }^{\star}$ \\ * Departments of Internal Medicine and Pathology, University of Texas Southwestern Medical Center, Dallas, Texas 75235-9034; and \\ ${ }^{\ddagger}$ Institute of Anatomy, University of Bern, CH-3000, Bern, Switzerland
}

\begin{abstract}
To determine if the functional compensation in diffusing capacity of the remaining lung following pneumonectomy is due to structural growth, we performed morphometric analysis of the right lung in three adult foxhounds $\sim 2$ yr after left pneumonectomy (removal of $\mathbf{4 2 \%}$ of lung) and compared the results to those in normal adult dogs previously studied by the same techniques. Diffusing capacity was calculated by an established morphometric model and compared to physiologic estimates at peak exercise in the same dogs after pneumonectomy. The major structural changes after left pneumonectomy are hyperinflation of the right lung, alveolar enlargement, and thinning of the alveolar-capillary tissue barrier. These changes confer significant functional compensation for gas exchange by reducing the overall resistance to $\mathrm{O}_{2}$ diffusion. The magnitude of compensation in diffusing capacity estimated either morphometrically or physiologically is similar. In spite of morphometric and physiologic evidence of functional compensation, there is no evidence of significant growth of structural components. After pneumonectomy, morphometric estimates of diffusing capacity are on average $23 \%$ higher than physiologic estimates in the same dogs at peak exercise. We conclude that the previously reported large differences between morphometric and physiologic estimates of diffusing capacity reflects the presence of large physiologic reserves available for recruitment. (J. Clin. Invest. 1993. 92:758-764.) Key words: morphometry • rebreathing $\bullet$ lung resection $\bullet$ exercise $\bullet$ recruitment
\end{abstract}

\section{Introduction}

Left pneumonectomy removes $42 \%$ of the pulmonary gas exchange units $(1,2)$ and thus would be expected to significantly reduce maximal oxygen uptake. This is particularly important in dogs that appear to have a small amount of redundancy in their gas exchanger for meeting oxygen demands at heavy exercise (3). However, in previous studies on dogs, we have observed that exercise performance is not significantly impaired by left pneumonectomy (4). Diffusing capacity for carbon

Parts of this work have been published in abstract form (1991. Clin. Res. 39:226A).

Address correspondence to Connie C. W. Hsia, M.D., Division of Pulmonary Research, Department of Internal Medicine, University of Texas Southwestern Medical Center, 5323 Harry Hines Boulevard, Dallas, TX 75235-9034.

Received for publication 20 October 1992 and in revised form 26 January 1993.

J. Clin. Invest.

(c) The American Society for Clinical Investigation, Inc.

0021-9738/93/08/0758/07 \$2.00

Volume 92, August 1993, 758-764 monoxide $\left(\mathrm{DL}_{\mathrm{CO}}\right)^{1}$ measured physiologically at peak exercise is reduced by only $23 \%$ after left pneumonectomy compared with before, suggesting that $\mathrm{DL}_{\mathrm{CO}}$ of the remaining lung must have increased by some $30 \%$ above that of the same lung before pneumonectomy (5). Two general sources of compensation are available to the remaining lung that could have accounted for the increase in $\mathrm{DL}_{\mathrm{Co}}$ after pneumonectomy: $(a)$ greater utilization of existing physiological reserves of $\mathrm{DL}_{\mathrm{Co}}$; and $(b)$ growth of new gas exchange tissue.

Diffusing capacity of the lung may be estimated physiologically by the rate of disappearance of carbon monoxide from the inspired gas by the single breath or the rebreathing technique. Large reserves of diffusing capacity normally exist in the lung and can be used during exercise as pulmonary blood flow and lung volume increase (5). The anatomical basis of recruitment of diffusing capacity has not been fully defined, but is presumed to be due to the unfolding of alveolar-capillary membrane (6), opening and/or the distention of pulmonary capillaries (7), and an increase in hematocrit (8). Diffusing capacity of the lung may also be estimated from morphometric measurements of the total alveolar-capillary surface area, the effective thickness of the diffusion barrier, and the pulmonary capillary red cell volume in the lung. Assuming that these diffusion barriers are arranged in series, these anatomical data have been used to give an estimate of diffusing capacity for $\mathrm{O}_{2}$ $\left(\mathrm{DL}_{\mathrm{O} 2}\right)$ and for carbon monoxide $\left(\mathrm{DL}_{\mathrm{CO}}\right)(9)$. The question arises whether postpneumonectomy functional compensation is solely due to physiological adjustments or whether it also involves structural adaptation; the latter may include altered characteristics of existing lung tissue or the addition of new lung tissue. The objective of our report is to determine whether and to what extent functional compensation of diffusing capacity in adult dogs after left pneumonectomy has been achieved by structural adjustments in the remaining lung. If the normal reserves of diffusing capacity in one lung is fully recruited after pneumonectomy, physiological estimates of $\mathrm{DL}_{\mathrm{CO}}$ at peak exercise should approximate morphometric estimate in the same animal. The extent of postpneumonectomy compensation estimated by either technique should be similar.

\section{Methods}

Animals. Extensive physiologic studies were performed in three adult male foxhounds (body wt 22-24 kg) before and after left pneumonectomy. These results have been reported in detail previously $(4$,

1. Abbreviations used in this paper: $\mathrm{DL}_{\mathrm{co}}$, diffusing capacity for carbon monoxide; $\mathrm{DL}_{\mathrm{O} 2}$, diffusing capacity for oxygen; $\mathrm{V}_{\mathrm{c}}$, pulmonary capillary blood volume; $V_{t}$, tissue volume; $V v(a, s)$, volume density of alveoli in septum; $\mathrm{Vv}(\mathrm{c}, \mathrm{s})$, volume density of capillaries in septum; $\mathrm{Vv}(\mathrm{cp}, \mathrm{L})$, volume density of coarse parenchyma in lung; $\mathrm{Vv}(\mathrm{fp}, \mathrm{cp})$, volume density of fine parenchyma in coarse parenchyma; $V v(s, f p)$, volume density of alveolar septa in fine parenchyma. 
$5,10-13)$. Dogs were trained to run on a treadmill up to maximal voluntary effort. Exercise training began before pneumonectomy, resumed $14 \mathrm{~d}$ after left pneumonectomy, and continued until killing. Physiologic studies at exercise were carried out before pneumonectomy and beginning at 4-6 mo after surgery; these consisted of measurements of ventilation, gas exchange including ventilation-perfusion relations, hemodynamics, and dynamic work of breathing at various lev-

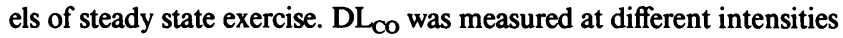
of steady state exercise by the rebreathing technique described previously in detail $(5,10)$. After the completion of physiologic studies $(\sim 2$ yr after pneumonectomy), the animals were killed and morphologic analysis of the remaining right lungs was carried out.

Lung fixation. The animal was deeply anesthetized with pentobarbital ( $25 \mathrm{mg} / \mathrm{kg}$ intravenously), intubated via a tracheostomy, and placed in the supine position. The abdomen was opened through a midline incision and a small rent made in the diaphragm to collapse the right lung. An overdose of pentobarbital was given and the lung immediately reinflated within the intact thorax by intratracheal instillation of $2.5 \%$ glutaraldehyde buffered with potassium phosphate to $\mathrm{pH} 7.40$ and osmolarity $350 \mathrm{mOsm}$ at a constant hydrostatic pressure of $25 \mathrm{~cm}$ $\mathrm{H}_{2} \mathrm{O}$ above the highest point of the sternum (14). After the flow of fixatives into the lung had stopped, the endotracheal tube was tightly clamped. After $60 \mathrm{~min}$ of fixation in situ, the thorax was opened; the lung and heart were removed en bloc and completely submerged in $10 \%$ buffered formaldehyde.

Sampling procedures. The previously established four-level stratified sampling scheme (15) was used: (I) gross, (II) low power light microscopic, (III) high power light microscopic, and (IV) electron microscopic analysis. The lungs were stratified according to lobe. Volume of each lobe was measured by water displacement. Each lobe was exhaustively sliced at $2-\mathrm{cm}$ intervals. Each slice was photographed using 35-mm Ektachrome color film to estimate the volume density of coarse parenchyma in lung, $\mathrm{Vv}(\mathrm{cp}, \mathrm{L})$, by quantifying all structures measuring $>1 \mathrm{~mm}$ (level I). Six blocks of tissue were taken from each lobe by a systematic, volume-weighted sampling procedure with a random start (15). Samples from each block were embedded in methacrylate for thick sections $(5 \mu \mathrm{m})$ stained with hematoxylin and eosin to estimate the volume density of fine parenchyma in coarse parenchyma, $\mathrm{Vv}(\mathrm{fp}, \mathrm{cp})$, by quantifying all structures measuring between $20 \mu \mathrm{m}$ and $1 \mathrm{~mm}$ (level II, $\times 200$ ). Additional samples from each block were embedded in Epon. These were used for preparation of semi-thin sections $(1 \mu \mathrm{m})$ to estimate the volume density of alveolar septa in fine parenchyma by light microscopy, $\mathrm{Vv}(\mathrm{s}, \mathrm{fp})$, by quantifying structures measuring $<20 \mu \mathrm{m}$ (level III, $\times 400$ ), and to estimate volume and surface densities of alveolar structures in septum, e.g., capillaries $\mathrm{Vv}(\mathrm{c}, \mathrm{s})$, alveoli $\operatorname{Vv}(\mathrm{a}, \mathrm{s})$, as well as harmonic mean thicknesses of plasma and tissue diffusion barriers by electron microscopy (level IV, $\times \sim 11,000$ ). Detail of the methods have been described previously (15).

Morphometric analysis. Slides at each level were placed under standard counting grids. Volume density of alveolar structures were determined by point counting. Surface density of alveoli and capillaries were determined by intersection counting. All morphometric data were calculated for each lobe separately; a volume-weighted average for the entire lung was then calculated. Absolute volume and surface area of individual alveolar structures were obtained by relating the respective volume and surface densities at each level back through the cascade of levels to the measured volume of the lobe (15).

Morphometric diffusing capacity for $\mathrm{O}_{2}\left(D L_{\mathrm{O} 2}\right)$. DL $\mathrm{OL}_{2}$ was estimated by the model previously described ( 9 ). The model describes the gas diffusion path from alveolar air to the binding sites on hemoglobin as three serially linked conductance steps through the tissue $\left(\mathrm{Dt}_{\mathrm{O} 2}\right)$, the plasma $\left(\mathrm{Dp}_{\mathrm{O} 2}\right)$, and the erythrocyte $\left(\mathrm{De}_{\mathrm{O} 2}\right)$ :

$$
\mathrm{DL}_{\mathrm{O} 2}^{-1}=\mathrm{Dt}_{\mathrm{O} 2}{ }^{-1}+\mathrm{Dp}_{\mathrm{O} 2}{ }^{-1}+\mathrm{De}_{\mathrm{O} 2}{ }^{-1}
$$

where

$$
\mathrm{Dt}_{\mathrm{O} 2}=\mathrm{Kt}_{\mathrm{O} 2} \cdot \frac{\left(\mathrm{S}_{\mathrm{A}}+\mathrm{S}_{\mathrm{c}}\right)}{\left(2 \cdot \tau_{\mathrm{ht}}\right)}
$$

$$
\begin{aligned}
& \mathrm{Dp}_{\mathrm{O} 2}=\mathrm{Kp}_{\mathrm{O} 2} \cdot \frac{\mathrm{Sc}}{\tau_{\mathrm{hp}}} \\
& \mathrm{De}_{\mathrm{O} 2}=\Theta_{\mathrm{O} 2} \cdot \mathrm{V}_{\mathrm{c}}
\end{aligned}
$$

$S_{A}$ and $S_{c}$ are the measured total alveolar and capillary surface area, and $V_{c}$ the measured total capillary blood volume. $\tau_{h t}$ and $\tau_{\mathrm{hp}}$ are the harmonic mean thicknesses of the tissue and plasma barriers, respectively. $\mathrm{Kt}_{\mathrm{O} 2}$ and $\mathrm{Kp}_{\mathrm{O} 2}$ are the $\mathrm{Krogh}$ diffusion coefficients for $\mathrm{O}_{2}$ in tissue and plasma, respectively; these were taken from literature and were the same as used previously (14). $\Theta_{\mathrm{O} 2}$ is the reaction rate of whole blood with $\mathrm{O}_{2}$ (in $\left.\mathrm{ml} \cdot(\mathrm{ml} \cdot \mathrm{mmHg} \cdot \mathrm{s})^{-1}\right)$. For the purpose of comparison, we used the same value of $\Theta_{\mathrm{O} 2}$ as used by Weibel et al. (14) in normal dogs, calculated from the equation:

$$
\begin{array}{r}
\Theta_{\mathrm{O} 2}=\mathrm{K}_{\mathrm{c}(60 \%)}^{\prime} \cdot \mathrm{f}(\mathrm{T}) \cdot\left(0.0587 \cdot \alpha_{\mathrm{O} 2}\right) \cdot\left(1-\mathrm{S}_{\mathrm{O} 2}\right) \\
\times(0.01333 \cdot[\mathrm{Hb}])
\end{array}
$$

where $\mathrm{K}_{\alpha 60 \%)}^{\prime}$ is the red cell reaction velocity at $60 \%$ saturation. The value of $K_{\alpha 60 \%)}^{\prime}$ measured by Holland et al. (16) is 220 $\mathrm{mM}^{-1} \cdot \mathrm{s}^{-1}$; however, more recent data have shown that the presence of an unstirred layer of plasma surrounding the red cell in the stop-flow technique may cause underestimation of the initial reaction rate by a factor of $\sim 2(17,18)$. Therefore, we used a value of $K_{\alpha 60 \%)}^{\prime}=440 \mathrm{mM}^{-1} \cdot \mathrm{s}^{-1}$ to take into account this effect. $f(T)$ is the temperature factor derived from the Arrhenius equation that corrects $K_{c}^{\prime}$ from the standard $37^{\circ} \mathrm{C}$ to the core temperature measured at peak exercise workload. $\alpha_{\mathrm{O} 2}$ is the solubility of $\mathrm{O}_{2}$ at the core temperature during peak exercise workload. $\mathrm{S}_{\mathrm{O} 2}$ is the initial fractional saturation of $\mathrm{O}_{2}$. [Hb] is the hemoglobin concentration in $\mathrm{g} / \mathrm{dl}$ of blood.

Morphometric diffusing capacity for $C O\left(D L_{C o}\right)$. $\mathrm{DL}_{\mathrm{Co}}$ was calculated using the same model described above (Eqs. 1-4) substituting $\mathrm{CO}$ for $\mathrm{O}_{2}$. Again, for the purpose of comparison with previous data, we used the same $\Theta_{\mathrm{CO}}$ as in the study by Weibel et al. (19), calculated from the equation given by Holland $(20,21)$ for $\operatorname{dog}$ blood at $40^{\circ} \mathrm{C}$, the core temperature expected of exercising dogs:

$$
\frac{1}{\Theta_{\mathrm{CO}}}=\left(0.929+0.00379 \mathrm{PA}_{\mathrm{O} 2}\right) \cdot \frac{14.4}{[\mathrm{Hb}]}
$$

$\Theta_{\mathrm{CO}}$ has the units of $\left[\mathrm{ml} \cdot(\mathrm{ml} \cdot \mathrm{mmHg} \cdot \mathrm{min})^{-1}\right] . \mathrm{PA}_{\mathrm{O} 2}$ is the mean alveolar $\mathrm{O}_{2}$ tension taken to be $100 \mathrm{mmHg}$. [ Hb] is taken to be $15 \mathrm{~g} / \mathrm{dl}$.

Data analysis. Since physiologic studies were performed before and after pneumonectomy on the same dogs, no simultaneous controls were available for morphometric measurements. Therefore, we compared morphometric results with published data by Weibel et al. (14) in three normal mongrel dogs using the same sampling and morphometric techniques by one-tailed unpaired $t$ test. Physiologic-morphometric comparison of $\mathrm{DL}_{\mathrm{CO}}$ was similarly related to those of Weibel et al. (19) in different species of normal canids. A $P$ value of $<0.05$ was considered significant.

\section{Results}

Morphometric measurements are shown in Table I. Volume compensation was essentially complete; the volume of one lung after pneumonectomy equaled that of two lungs in normal dogs. Morphometric hematocrit was significantly lower in 


\begin{tabular}{|c|c|c|c|}
\hline & & & $P$ values \\
\hline & $\begin{array}{l}\text { Dogs after left } \\
\text { pneumonectomy }\end{array}$ & $\begin{array}{c}\text { Normal } \\
\text { dogs }\end{array}$ & $\begin{array}{l}\text { Unpaired } \\
t \text { test }\end{array}$ \\
\hline Number & 3 & 3 & \\
\hline Body mass $(\mathrm{kg})$ & $23.8 \pm 0.6$ & $28.2 \pm 0.7$ & $0.004^{*}$ \\
\hline Total lung volume $\left(\mathrm{ml} \cdot \mathrm{kg}^{-1}\right)$ & $53.4 \pm 4.4$ & $56.3 \pm 1.9$ & 0.29 \\
\hline Right lung volume $\left(\mathrm{ml} \cdot \mathrm{kg}^{-1}\right)$ & $53.4 \pm 4.4$ & $32.7 \pm 1.1$ & $0.005^{*}$ \\
\hline Morphometric hematocrit (\%) & $43.5 \pm 3.3$ & $55.0 \pm 1.5$ & $0.02^{*}$ \\
\hline \multicolumn{4}{|l|}{ Volume density } \\
\hline Parenchyma in lung $V v(f p, L)$ & $0.850 \pm 0.001$ & $0.819 \pm 0.002$ & $0.0001^{*}$ \\
\hline Septa in parenchyma $\mathrm{Vv}(\mathrm{s}, \mathrm{fp})$ & $0.106 \pm 0.005$ & $0.157 \pm 0.008$ & $0.0009^{*}$ \\
\hline Capillaries in lung $\mathrm{Vv}(\mathrm{c}, \mathrm{L})$ & $0.058 \pm 0.005$ & $0.074 \pm 0.002$ & $0.02^{*}$ \\
\hline Tissue in lung $\mathrm{Vv}(\mathrm{t}, \mathrm{L})$ & $0.032 \pm 0.0003$ & $0.054 \pm 0.002$ & $0.0001^{*}$ \\
\hline \multicolumn{4}{|l|}{ Surface density } \\
\hline Alveoli in lung $\operatorname{Sv}(\mathrm{a}, \mathrm{L}) \mathrm{cm}^{-1}$ & $343.8 \pm 2.3$ & $488.5 \pm 10.4$ & $0.0001^{*}$ \\
\hline Capillaries in lung $\mathrm{Sv}(\mathrm{c}, \mathrm{L}) \mathrm{cm}^{-1}$ & $292.7 \pm 22.7$ & $385.0 \pm 6.6$ & $0.009^{*}$ \\
\hline \multicolumn{4}{|l|}{ Arithmetic mean thickness $\left(10^{-4} \mathrm{~cm}\right)$} \\
\hline Tissue barrier & $1.02 \pm 0.04$ & $1.24 \pm 0.02$ & $0.005^{*}$ \\
\hline Septum & $2.61 \pm 0.13$ & $2.63 \pm 0.05$ & 0.45 \\
\hline \multicolumn{4}{|l|}{ Harmonic mean thickness $\left(10^{-4} \mathrm{~cm}\right)$} \\
\hline Tissue barrier $\left(\tau_{\mathrm{ht}}\right)$ & $0.341 \pm 0.014$ & $0.509 \pm 0.019$ & $0.001^{*}$ \\
\hline Plasma barrier $\left(\tau_{\mathrm{hp}}\right)$ & $0.155 \pm 0.004$ & $0.117 \pm 0.001$ & $0.005^{*}$ \\
\hline \multicolumn{4}{|l|}{ Volumes $\left(\mathrm{ml} \cdot \mathrm{kg}^{-1}\right)$} \\
\hline Capillaries Total & $3.08 \pm 0.29$ & $4.18 \pm 0.18$ & $0.02^{*}$ \\
\hline Right lung & $3.08 \pm 0.29$ & $2.43 \pm 0.10$ & 0.05 \\
\hline Septum Total & $4.791 \pm 0.425$ & $7.238 \pm 0.351$ & $0.005^{*}$ \\
\hline Right lung & $4.791 \pm 0.425$ & $4.198 \pm 0.203$ & 0.14 \\
\hline Tissue Total & $1.711 \pm 0.159$ & $3.055 \pm 0.179$ & $0.003^{*}$ \\
\hline Right lung & $1.711 \pm 0.159$ & $1.772 \pm 0.104$ & 0.38 \\
\hline \multicolumn{4}{|l|}{ Surface area $\left(\mathrm{m}^{2} \cdot \mathrm{kg}^{-1}\right)$} \\
\hline Alveoli Total & $1.836 \pm 0.142$ & $2.756 \pm 0.145$ & $0.005^{*}$ \\
\hline Right lung & $1.836 \pm 0.142$ & $1.598 \pm 0.084$ & 0.11 \\
\hline Capillaries Total & $1.564 \pm 0.174$ & $2.167 \pm 0.069$ & $0.02^{*}$ \\
\hline Right lung & $1.564 \pm 0.174$ & $1.257 \pm 0.040$ & 0.08 \\
\hline
\end{tabular}

Results are mean \pm SEM. * Significant at 0.05 level.

pneumonectomized dogs. Volume densities of all septal structures were significantly lower in pneumonectomized animals than in controls, indicating alveolar hyperinflation, stretching and thinning of the alveolar septum which is evident under low power magnification (Fig. 1). Surface densities of alveoli and capillaries were significantly lower than normal. Arithmetic mean thickness of the tissue barrier was significantly lower in pneumonectomized dogs but the mean thickness of the septum was similar to that in controls. The harmonic mean thickness of the tissue barrier was also lower in pneumonectomized animals than in controls. Harmonic mean thickness of the plasma barrier was greater in pneumonectomized animals owing to the lower hematocrit. In pneumonectomized dogs, total volumes of the capillary blood and the septum were significantly reduced to 74 and $66 \%$ of normal, respectively; total septal tissue volume was reduced to $56 \%$ of normal. Total surface area of the alveoli and capillaries were also significantly reduced to 66 and $72 \%$ of normal, respectively. There were no significant differences in morphometric parameters among lobes.

Estimations of $\mathrm{DL}_{\mathrm{O} 2}$ and $\mathrm{DL}_{\mathrm{CO}}$ are shown in Table II. In the pneumonectomized group, $\mathrm{Dt}_{\mathrm{O} 2}$ and $\mathrm{Dm}_{\mathrm{O} 2}$ were not signifi- cantly different ( $88 \%)$ from that of two lungs in normal dogs. $\mathrm{De}_{\mathrm{O} 2}$ was significantly lower due to a lower $\mathrm{Vc} \mathrm{DL}_{\mathrm{O} 2}$ was lower $(81 \%)$ than normal at a borderline significance $(P=0.07)$. Similar changes are seen in the components of $\mathrm{DL}_{\mathrm{CO}}$.

The right lung in the dog constitutes on average $58 \%$ of total lung volume and weight, and receives a similar percentage of total ventilation and blood flow $(1,2,22,23)$. Our results in the right lung of dogs after pneumonectomy may be compared to that in the right lung of normal dogs by multiplying results in normal dogs by a factor of 0.58 . This comparison is shown in Fig. 2. Compared with the expected value in the normal right lung, morphometric parameters (Fig. $2 a$ ) including surface area of the alveoli and capillaries, and volumes of capillaries and septum, were on average $15-26 \%$ higher after pneumonectomy and reached borderline statistical significance (Table I). Tissue volume $(\mathrm{Vt})$ was not different from that in the normal right lung. Similar comparisons of components of diffusing capacity of the right lung showed that $\mathrm{De}_{\mathrm{O} 2}, \mathrm{Dm}_{\mathrm{O} 2}$, and $\mathrm{DL}_{\mathrm{O} 2}$ were significantly higher in postpneumonectomy dogs (Fig. 2 $b$ ); $\mathrm{De}_{\mathrm{CO}}, \mathrm{Dm}_{\mathrm{CO}}$, and $\mathrm{DL}_{\mathrm{CO}}$ were also significantly higher in postpneumonectomy dogs (Fig. $2 c$ ). 

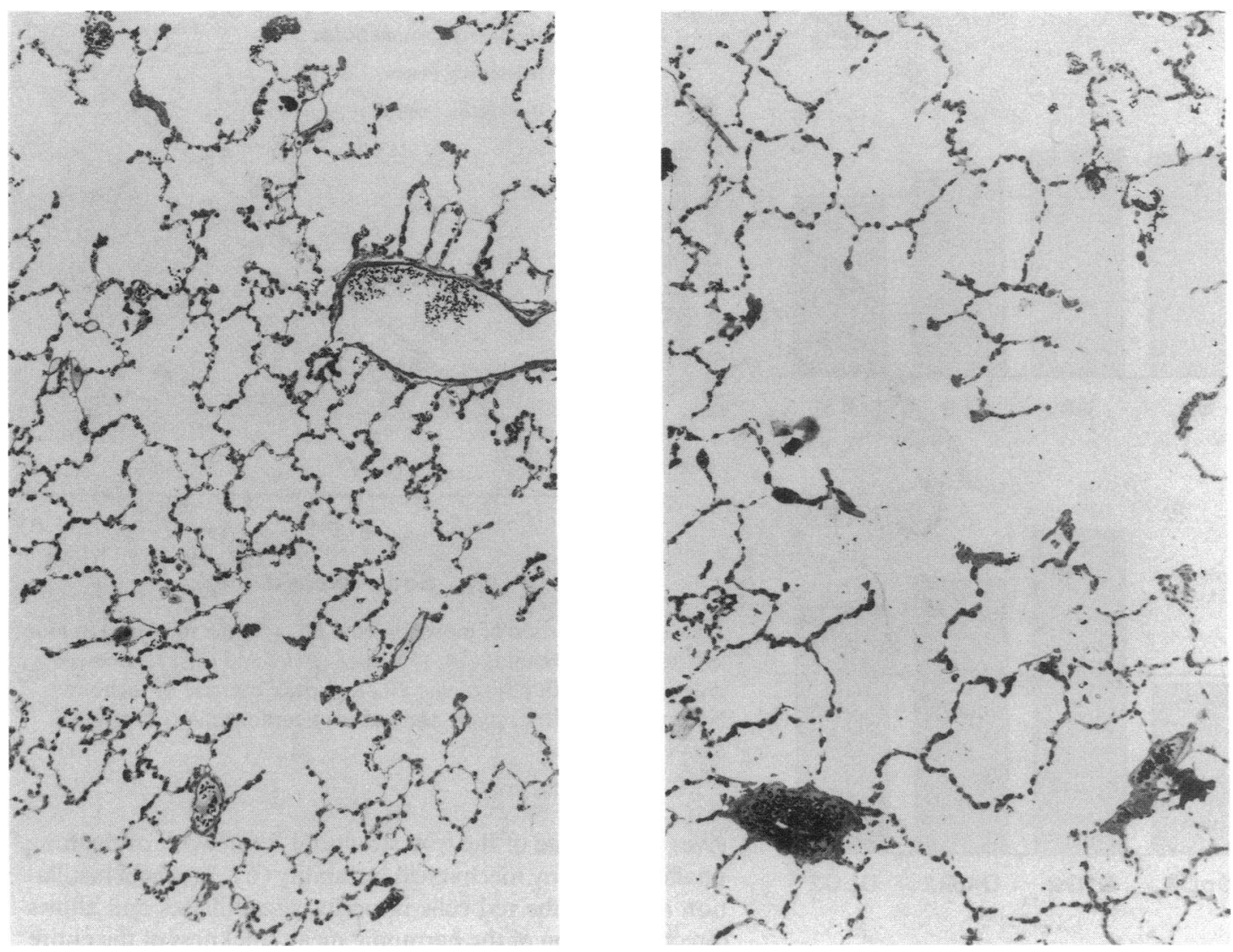

Figure 1. Photomicrograph $(\times 100)$ of lung parenchyma in normal dog (left panel $)$ and in a dog after left pneumonectomy (right panel $)$.

Physiologic $\mathrm{DL}_{\mathrm{co}}$ measured by the rebreathing technique in these dogs before and after left pneumonectomy have been previously published $(5,12)$. A linear relationship between $\mathrm{DL}_{\mathrm{CO}}$ and $\mathrm{O}_{2}$ uptake and between $\mathrm{DL}_{\mathrm{CO}}$ and pulmonary blood

Table II. Components of Diffusing Capacity Calculated from Morphometric Measurements in the Right Lung of Dogs after Left Pneumonectomy and in Both Lungs of Normal Dogs

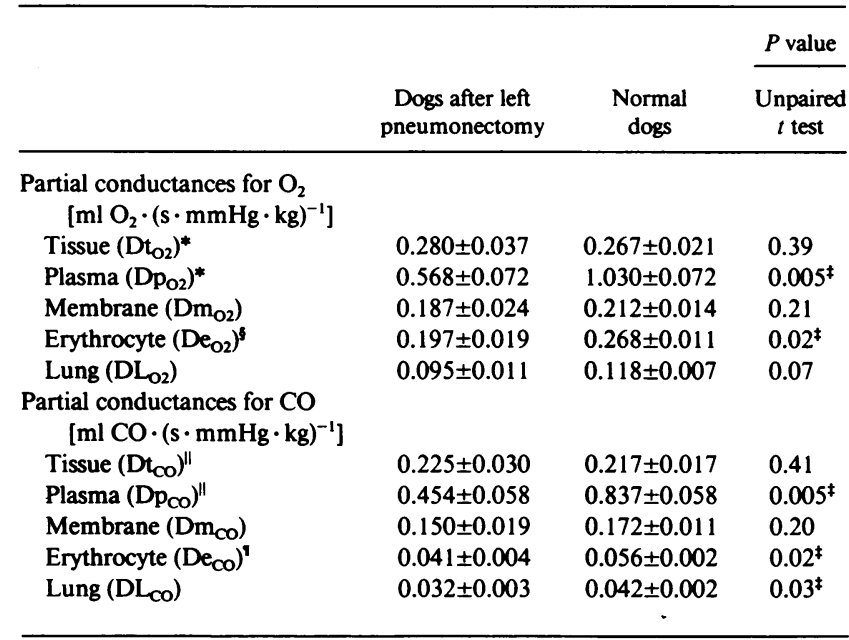

Results are mean \pm SEM. ${ }^{*} \mathrm{Kt}_{\mathrm{O} 2}$ and $\mathrm{Kp}_{\mathrm{O} 2}=5.5 \times 10^{-10}$ $\mathrm{cm}^{2} \cdot \mathrm{s}^{-1} \cdot \mathrm{mmHg}^{-1}$. ${ }^{\ddagger}$ Significant at 0.05 level. ${ }^{\S} \theta_{\mathrm{O} 2}=0.0641$ $\mathrm{ml} \cdot(\mathrm{ml} \cdot \mathrm{mmHg} \cdot \mathrm{s})^{-1}$. ${ }^{1} \mathrm{Kt}_{\mathrm{CO}}$ and $\mathrm{Kp} \mathrm{coO}=4.467 \times 10^{-10}$ $\mathrm{cm}^{2} \cdot \mathrm{s}^{-1} \cdot \mathrm{mmHg}^{-1} \cdot{ }^{\prime} \theta_{\mathrm{co}}=0.0133 \mathrm{ml} \cdot(\mathrm{ml} \cdot \mathrm{mmHg} \cdot \mathrm{s})^{-1}$. flow is evident in each dog. The highest $\mathrm{DL}_{\mathrm{co}}$ obtained in each dog at exercise before and after pneumonectomy are shown in Fig. 3 in comparison with morphometric estimates from normal canids $(14,19)$. In the present dogs, the ratio of physiologic $\mathrm{DL}_{\mathrm{CO}}$ after pneumonectomy to that in the same right lung before pneumonectomy is $1.28,1.21$, and 1.30 in each of the three dogs, with an average ratio of 1.27 . The ratio of morphometric $\mathrm{DL}_{\mathrm{CO}}$ in postpneumonectomy dogs to that in the right lung of normal dogs is also 1.27. Fig. 4 shows the $\mathrm{DL}_{\mathrm{CO}}$ estimated postpneumonectomy by rebreathing at exercise and by morphometry postmortem in each of the three dogs. On the average, morphometric estimates are $23 \%$ higher than physiologic estimates in the same dog.

\section{Discussion}

Summary of findings. This is the first study correlating morphometric compensation with physiologic compensation at heavy exercise in the same dogs after extensive lung resection. At two years after left pneumonectomy, equivalent to the removal of about $42 \%$ of lung, the major morphological changes are hyperinflation of the remaining lung, enlargement of the alveolar air spaces, and thinning of the alveolar-capillary tissue barrier. These changes confer significant functional compensation for gas exchange by reducing the overall resistance for $\mathrm{O}_{2}$ diffusion. Postpneumonectomy compensatory increase in diffusing capacity was the same $(27 \%)$ when estimated by physiologic and morphometric techniques. In spite of significant morphometric and physiologic evidence for functional compensation, there is no evidence of significant growth of 

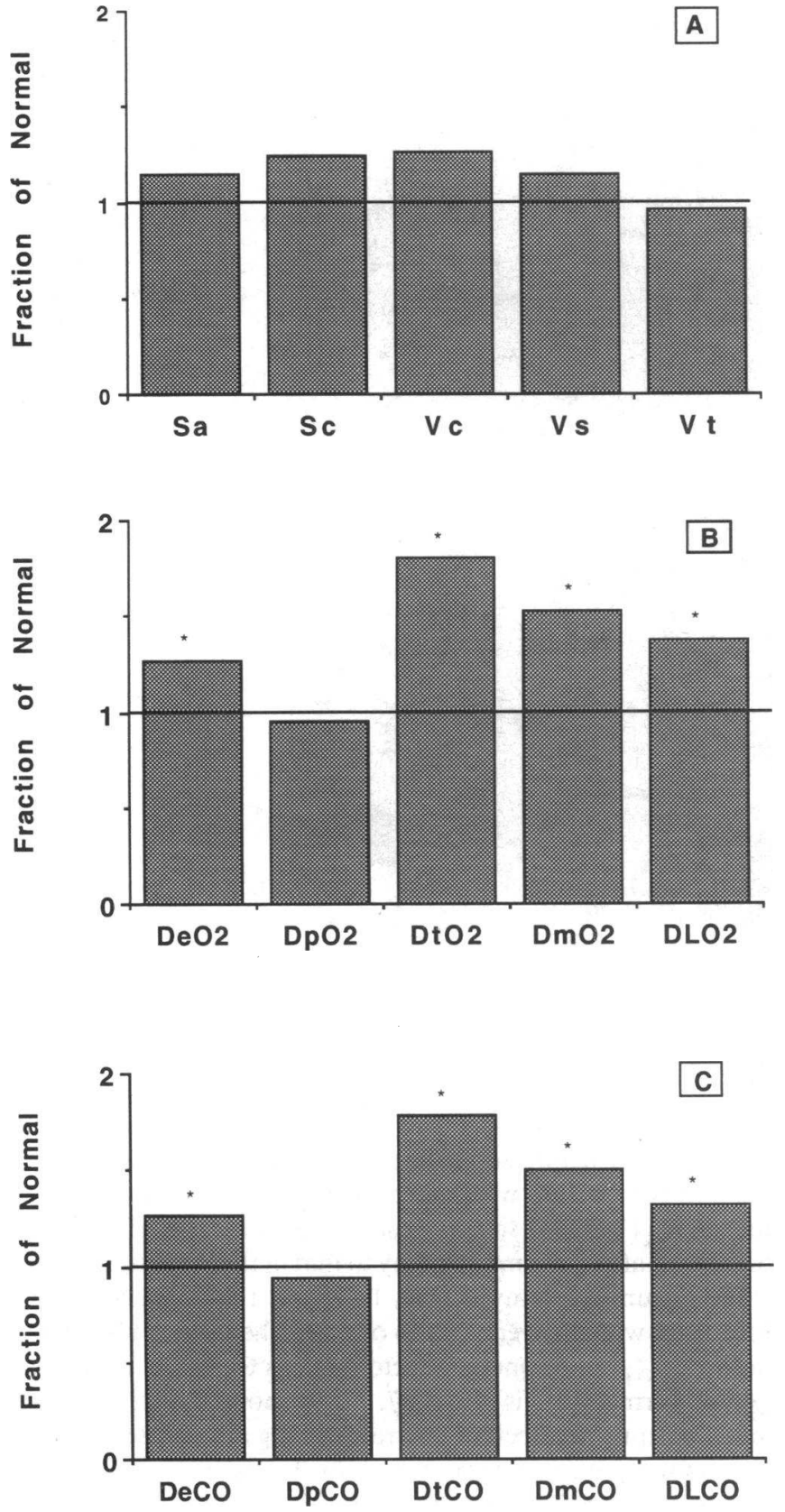

Figure 2. Comparison of morphometric estimate in the right lung of dogs after pneumonectomy expressed as a fraction of expected normal value in the right lung of normal dogs. ( $A) S a, S c$, surface area of alveoli and capillaries, respectively. $V c, V s, V t$, volume of capillaries, septum, and tissue, respectively. $(B)$ Components of diffusing capacity for $\mathrm{O}_{2}$. $(C)$ Components of diffusing capacity for $\mathrm{CO}$. ${ }^{*}$ Significantly different from unity.

pulmonary structural components. There is a good correlation between $\mathrm{DL}_{\mathrm{Co}}$ estimated by morphometric and by physiologic techniques at peak exercise in normal dogs and in dogs after pneumonectomy. Morphometric $\mathrm{DL}_{\mathrm{CO}}$ is $\sim 23 \%$ higher than physiologic $\mathrm{DL}_{\mathrm{co}}$ at peak exercise in the same animals.

Critique of methods. Tracheal instillation of fixatives was chosen over perfusion fixation because the former leads to complete unfolding of the alveolar capillary membrane and

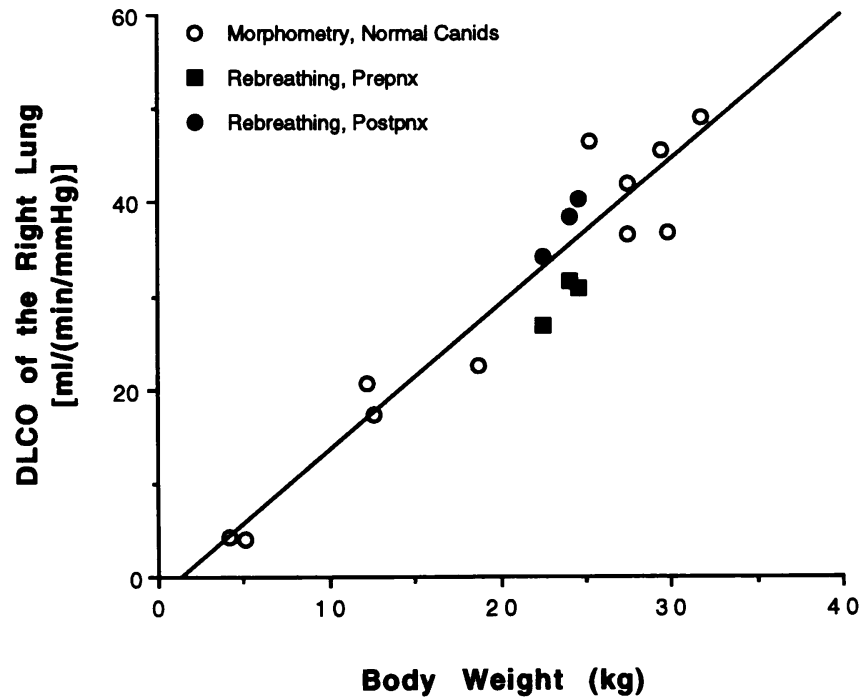

Figure 3. Comparison of morphometric $\mathrm{DL}_{\infty}$ of the right lung in four species of normal canids $(14,19)$ (open circles and least squares regression line) with physiologic $\mathrm{DL}_{\mathrm{co}}$ at peak exercise in foxhounds before (prepnx, dark squares) and after pneumonectomy (postpnx, dark circles) (5).

gives an estimate of the true structural framework of the lung unaffected by any mechanical instability ( 6 ). Tracheal instillation also fixes the red cells in perfused capillaries and allows direct estimation of the harmonic mean thickness of the entire diffusion path, including the plasma barrier which cannot be measured after perfusion fixation. Since physiologic measurements were obtained in these foxhounds both before and after left pneumonectomy, no simultaneous control animals were available for morphometric analysis. However, the published control data used (14) were obtained using the same techniques of fixation, sampling, and analysis as in the present report. In different species of canids, Weibel et al. $(14,19)$

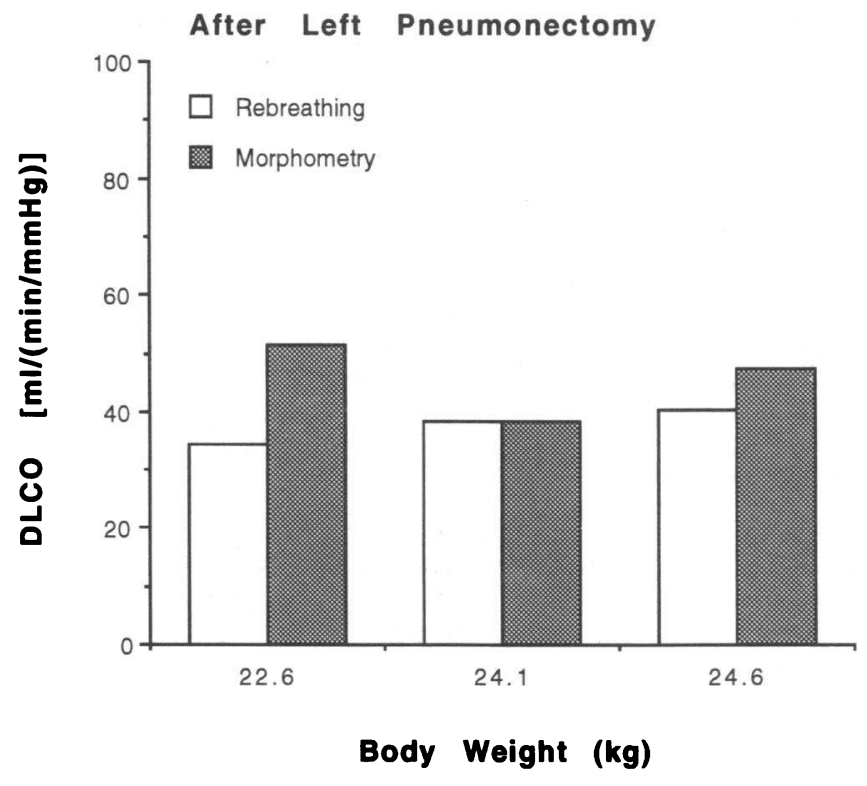

Figure 4. Comparison of physiologic $\mathrm{DL}_{\mathrm{Co}}$ at peak exercise (5) and morphometric $\mathrm{DL}_{\mathrm{Co}}$ in the same foxhounds after pneumonectomy. 
found that differences in morphometric estimates are directly related to body weight. Thus comparisons between foxhounds and mongrel dogs should be valid when results are normalized by body weight, particularly since differences in body weight between these two species are small. The true value of $\Theta$ remains controversial. $\Theta$ for $\mathrm{CO}$ has been measured by several independent methods, yielding similar values in man and dog $(21,24-26)$. Thus variability in measurements of $\Theta_{\mathrm{CO}}$ is small. On the other hand, the in vitro measurement of $\Theta$ for $\mathrm{O}_{2}$ is more susceptible to artifact than $\Theta_{\mathrm{Co}}$ because reaction velocities for $\mathrm{O}_{2}$ are faster. However, errors in the estimation of $\Theta_{\mathrm{O} 2}$ does not affect the interpretation of our data since the same value of $\Theta_{\mathrm{O} 2}$ was used in the two groups. After completion of measurements of diffusing capacity, these dogs underwent implantation of a left atrial catheter for the measurement of respiratory muscle blood flow $\sim 6$ wk before killing (13). Anemia developed as a result of chronic catheter implantation; arterial hematocrit at rest was $43.8 \pm 1.4 \%$ before and $37.3 \pm 1.8 \%$ ( mean \pm SE) after catheter implantation. This anemia contributed to a slightly lower plasma component of diffusing capacity $\left(\mathrm{DpO}_{2}\right.$ and $\left.\mathrm{Dp}_{\mathrm{co}}\right)$. However, all physiologic measurements of diffusing capacity were expressed at a uniform hemoglobin concentration of $14.9 \mathrm{~g} / \mathrm{dl}$, close to that used in morphometric calculations.

Compensatory lung growth in adult dogs after pneumonectomy. Significant compensatory growth of gas exchange structures should result in higher surface areas of alveoli and capillaries, as well as higher volumes of septum, tissue, and capillaries than in the normal right lung. As shown in Fig. 2 in our dogs after pneumonectomy, these parameters are in general slightly higher than normal, reaching borderline statistical significance. There is no increase in lung tissue volume. The modest increase in surface area and volume of capillaries is consistent with either opening or distention of existing capillary bed by the diversion of the entire cardiac output through the remaining lung after pneumonectomy, but could also reflect the formation of new capillary loops when the septa become expanded. Thus the present study supports the conclusion from previous studies of a limited structural compensation in dogs after left pneumonectomy as adults $(27,28)$. In addition, we demonstrate the functional consequence of passive structural adaptation to lung resection. Enlargement of existing alveolar spaces and thinning of the alveolar septa result in a lower harmonic mean thickness of the tissue barrier $\left(\tau_{\mathrm{ht}}\right)$ and a significant increase in the gas conductance of the tissue barrier $\left(\mathrm{Dt}_{\mathrm{O} 2}\right)$ and of the membrane barrier $\left(\mathrm{Dm}_{\mathrm{O} 2}\right)$. Opening or distention of the pulmonary capillaries results in a significant increase in gas conductance of the erythrocyte component $\left(\mathrm{De}_{\mathrm{O} 2}\right)$. Hence the apparent morphometric diffusing capacity of the remaining lung is increased by an average of $27 \%$, a value similar to the average compensatory increase obtained by physiologic methods at peak exercise in the same animals.

Comparison of morphometric and physiologic $D L_{C o}$. Weibel et al. (19), using airway instillation of fixatives, compared $\mathrm{DL}_{\mathrm{CO}}$ estimated by morphometry and by the single breath method at rest in various species of canids; morphometric $\mathrm{DL}_{\mathrm{CO}}$ was found to be approximately twice that of physiologic $\mathrm{DL}_{\mathrm{CO}}$ in the same animal. Crapo et al. (29), also using airway instillation of fixative, compared $\mathrm{DL}_{\mathrm{CO}}$ by morphometry and by the rebreathing technique at rest in the same dogs; morphometric estimates are nearly three times higher than physiologic estimates. The large difference between techniques persists in lungs fixed by the perfusion technique (24), and appears to be due to a difference in the estimate of membrane diffusing capacity $\left(\mathrm{Dm}_{\mathrm{Co}}\right)$ which is nearly 10 times larger by morphometry than by the rebreathing method. By morphometric technique, $\mathrm{Dm}_{\mathrm{CO}}$ has been estimated to be $\sim 10$-fold larger than $\mathrm{Dm}_{\mathrm{CO}}$ estimated by the Roughton-Forster method in the dog at rest $(29,30)$. Estimates of pulmonary capillary blood volume ( Vc) by the two techniques at rest are about the same. In contrast, when we studied the present foxhounds before pneumonectomy, physiologic $\mathrm{DL}_{\mathrm{CO}}$ increased by more than threefold from rest to peak exercise and reached the normal range of morphometric estimates (Fig. 3). After pneumonectomy, $\mathrm{DL}_{\mathrm{CO}}$ by morphometry is on average only $23 \%$ higher than that estimated physiologically in the same animal, a closer agreement than any previous comparison.

One possible explanation for the discrepancy in comparisons of $\mathrm{DL}_{\mathrm{CO}}$ and $\mathrm{Dm}_{\mathrm{CO}}$ by these techniques is the existence of physiological reserves of diffusing capacity that are not normally used at rest, but may be mobilized for $\mathrm{O}_{2}$ transport upon exercise and after pneumonectomy. Morphometric estimates using intratracheal instillation of fixatives causes the unfolding of alveolar-capillary membranes (6); all capillaries, including those devoid of red cells, are included in the calculation of diffusing capacity. Hence morphometric estimates more closely reflect the structural capacity where all alveoli and capillaries are available for gas exchange. On the other hand, in vivo videomicroscopic observations by Wagner and colleagues (7) indicate that there is a progressive increase in the number of perfused capillary segments as pulmonary pressure is increased. Wagner's data suggest that capillaries are not fully recruited under normal resting conditions. After pneumonectomy, physiologic reserves of diffusing capacity in the remaining lung must be used since the entire cardiac output must now flow through one lung at any given work load. Thus the limit of structural capacity for gas exchange in the remaining lung may be more readily approached during heavy exercise. In previous publications ( 5 ) we showed that physiologic diffusing capacity increases two- to threefold from rest to heavy exercise, a change similar in magnitude to the difference between morphometric and resting physiologic measurements. Our interpretation is that morphometric $\mathrm{DL}_{\mathrm{co}}$ reflects the maximum structural capacity for gas exchange, a limit not physiologically approached except perhaps during very heavy exercise $(3,5)$. Hence the difference between morphometric $\mathrm{DL}_{\mathrm{CO}}$ and physiologic $\mathrm{DL}_{\mathrm{CO}}$ at rest represents functional reserves potentially available for recruitment upon exercise. After pneumonectomy, $\mathrm{DL}_{\mathrm{co}}$ continues to increase beyond that achieved before pneumonectomy as a result of a higher pulmonary blood flow through the remaining lung at any given workload. Although no clear plateau in the linear rise of $\mathrm{DL}_{\mathrm{CO}}$ is observed up to peak exercise equivalent to a cardiac output of 35 liters $\cdot \mathrm{min}^{-1}$ through two lungs, functional reserves in the remaining lung are insufficient to meet the demands for $\mathrm{O}_{2}$ transport, evidenced by arterial $\mathrm{O}_{2}$ desaturation due to diffusion limitation at moderate and heavy workloads after pneumonectomy (4). Furthermore, the pattern of decline in arterial $\mathrm{O}_{2}$ saturation after pneumonectomy could be predicted from physiologically measured $\mathrm{DL}_{\mathrm{CO}}(12)$. The severity of arterial $\mathrm{O}_{2}$ desaturation is mitigated by a concomitant reduction in maximal cardiac output. Under these conditions, a closer agreement between physiological and morphometric estimates of $\mathrm{DL}_{\mathrm{CO}}$ can be expected.

An alternative explanation is that the morphometric model 
may overestimate true $\mathrm{Dm}_{\mathrm{Co}}$. So called resistance of the membrane to $\mathrm{CO}$ uptake $\left(1 / \mathrm{Dm}_{\mathrm{CO}}\right)$ may be conceptualized as the sum of multiple resistances in series, i.e., resistances of the gas phase, the surfactant layer, the tissue, and plasma. The present morphometric model includes only the last two components; physiologic measurements include all. If diffusion resistance in the gas phase is significant, overexpansion of the lung after pneumonectomy should increase gas phase resistance and partially offset the apparent compensatory increase in $\mathrm{DL}_{\mathrm{co}}$ due to thinning of the tissue barrier and to capillary recruitment. In addition, the gas diffusion coefficients of compressed or homogenized lung used to estimate morphometric $\mathrm{Dm}_{\mathrm{Co}}$ (31) may be significantly greater than those of in vivo alveolar membranes in which surfactant monolayers remain intact; surfactant monolayers at an air-surface interface may potentially increase the resistance to gas permeation. The present study was not designed to clarify the contribution of these opposing influences.

In conclusion, we report that in adult dogs after left pneumonectomy, compensation by tissue growth is quite limited. However, adjustments in existing structures of the remaining lung, including hyperinflation, thinning of the tissue barrier, and capillary recruitment after pneumonectomy result in a significant compensatory increase in diffusing capacity which contributes significantly to the overall functional compensation. The degree of functional compensation estimated by either morphometric or physiologic technique is similar. We found a closer agreement between estimates of $\mathrm{DL}_{\mathrm{CO}}$ by morphometric and by physiologic methods than previously reported, possibly because our physiological measurements were performed during heavy exercise when nearly all of existing functional reserves are exploited. The large discrepancy between these techniques reported in earlier studies is at least partly due to the failure to take into account the existence of functional reserves in diffusing capacity.

\section{Acknowledgment}

We wish to dedicate this manuscript to the memory of Dr. Rolland C. Reynolds; his kindness, support, and friendship are dearly missed. We also express our gratitude to Anna Siler, David Treakle, and Barbara Kalley-Taylor for their technical assistance.

This project was supported by the National Heart Lung and Blood Institute (HL-40070) and by the Swiss National Science Foundation (3.172.88).

\section{References}

1. Rahn, H., P. Sadoul, L. E. Farhi, and J. Shapiro. 1956. Distribution of ventilation and perfusion in the lobes of the dog's lung in the supine and erect position. J. Appl. Physiol. 8:417-426.

2. Rahn, H., and B. B. Ross. 1957. Bronchial tree casts, lobe weights and anatomical dead space measurements in the dog's lung. J. Appl. Physiol. 10:154 157.

3. Karas, R. H., C. R. Taylor, J. H. Jones, S. L. Lindstedt, R. B. Reeves, and E. R. Weibel. 1987. Adaptive variation in the mammalian respiratory system in relation to energetic demand. VII. Flow of oxygen across the pulmonary gas exchanger. Respir. Physiol. 69:101-115.

4. Hsia, C. C. W., J. I. Carlin, P. D. Wagner, S. S. Cassidy, and R. L. Johnson, Jr. 1990. Gas exchange abnormalities after pneumonectomy in conditioned foxhounds. J. Appl. Physiol. 68:94-104.

5. Carlin, J. I., C. C. W. Hsia, S. S. Cassidy, M. Ramanathan, P. S. Clifford, and R. L. Johnson, Jr. 1991. Recruitment of lung diffusing capacity with exercise before and after pneumonectomy in dogs. J. Appl. Physiol. 70:135-142.
6. Gil, J., H. Bachofen, P. Gehr, and E. R. Weibel. 1979. Alveolar volume-surface area relation in air- and saline-filled lungs fixed by vascular perfusion. $J$. Appl. Physiol. 47:990-1001.

7. Wagner, W. W., L. P. Latham, and R. L. Capen. 1979. Capillary recruitment during airway hypoxia: role of pulmonary artery pressure. J. Appl. Physiol. 47:383-387.

8. Malvin, G. M. and S. C. Wood. 1992. Effects of capillary red cell density on gas conductance of frog skin. J. Appl. Physiol. 73:224-233.

9. Weibel, E. R. 1970. Morphometric estimation of pulmonary diffusion capacity. I. Model and method. Respir. Physiol. 11:54-75.

10. Carlin, J. I., S. S. Cassidy, U. Rajagopal, P. S. Clifford, and R. L. Johnson, Jr. 1988. Noninvasive diffusing capacity and cardiac output in exercising dogs. $J$. Appl. Physiol. 65:669-674.

11. Hsia, C. C. W., J. I. Carlin, S. S. Cassidy, M. Ramanathan, and R. L. Johnson, Jr. 1990. Hemodynamic changes after pneumonectomy in the exercising foxhound. J. Appl. Physiol. 69:51-57.

12. Hsia, C. C. W., J. I. Carlin, M. Ramanathan, S. S. Cassidy, and R. L. Johnson, Jr. 1991. Estimation of diffusion limitation after pneumonectomy from carbon monoxide diffusing capacity. Respir. Physiol. 83:11-21.

13. Hsia, C. C. W., M. Ramanathan, J. L. Pean, and R. L. Johnson, Jr. 1992. Respiratory muscle blood flow in exercising dogs after pneumonectomy. J. Appl. Physiol. 73:240-247.

14. Weibel, E. R., L. B. Marques, M. Constantinopol, F. Doffey, P. Gehr, and C. $R$. Taylor. 1987. Adaptive variation in the mammalian respiratory system in relation to energetic demand. VI. The pulmonary gas exchanger. Respir. Physiol. 69:81-100.

15. Weibel, E. R. 1984. Morphometric and stereological methods in respiratory physiology, including fixation techniques. In Techniques in the Life Sciences. Respiratory Physiology. A. B. Otis, editor. Elsevier/Scientific Publishers Ireland Inc., Limerick. P401:1-35.

16. Holland, R. A. B., W. Van Hezewijk, and J. Zubzanda. 1977. Velocity of oxygen uptake by partly saturated adult and fetal human red cells. Respir. Physiol. 29:303-314.

17. Holland, R. A., H. Shibata, P. Scheid, and J. Piiper. 1985. Kinetics of $\mathrm{O}_{2}$ uptake and release by red cells in stopped-flow apparatus: effects of unstirred layer. Respir. Physiol. 59:71-91.

18. Yamaguchi, K., P. D. Nguyen, P. Scheid, and J. Piiper. 1985. Kinetics of $\mathrm{O}_{2}$ uptake and release by human erythrocytes studied by a stopped-flow technique. J. Appl. Physiol. 58:1215-1224.

19. Weibel, E. R., C. R. Taylor, J. J. O'Neil, D. E. Leith, P. Gehr, H. Hoppeler, V. Langman, and R. V. Baudinette. 1983. Maximal oxygen consumption and pulmonary diffusing capacity: a direct comparison of physiologic and morphometric measurements in canids. Respir. Physiol. 54:173-188.

20. Holland, R. A. B. 1969. Rate of $\mathrm{O}_{2}$ dissociation from $\mathrm{O}_{2} \mathrm{Hb}$ and relative combination rate of $\mathrm{CO}$ and $\mathrm{O}_{2}$ in mammals at $37^{\circ} \mathrm{C}$. Respir. Physiol. 7:30-42.

21. Holland, R. A. B. 1969. Rate at which CO replaces $\mathrm{O}_{2}$ from $\mathrm{O}_{2} \mathrm{Hb}$ in red cells of different species. Respir. Physiol. 7:43-63.

22. Massion, W. H., D. R. Caldwell, N. A. Early, and J. A. Schilling. 1962. The relationship of dry lung weights to pulmonary function in dogs and humans. $J$. Surg. Res. 2:287-292.

23. Schilling, J. A. 1965. Pulmonary resection and sequelae of thoracic surgery. In Handbook of Physiology, W. O. Fenn and H. Rahn, editors. Section 3: Respiration. Vol. 2. The American Physiological Society, Washington, DC. 1531-1563.

24. Reeves, R. B. and H. K. Park. 1992. CO uptake kinetics of red cells and CO diffusing capacity. Respir. Physiol. 88:1-21.

25. Roughton, F. J. W., R. E. Forster, and L. Cander. 1957. Rate at which carbon monoxide replaces oxygen from combination with human hemoglobin in solution and in the red cell. J. Appl. Physiol. 11:269-276.

26. Crapo, R. O., N. Bitterman, S. L. Berlin, and R. E. Forster. 1989. Rate of $\mathrm{CO}$ uptake by canine erythrocytes as a function of $\mathrm{PO}_{2}$. J. Appl. Physiol. 67:2265-2268.

27. Davies, P., J. McBride, G. F. Murray, B. R. Wilcox, J. A. Shallal, and L. Reid. 1982. Structural changes in the canine lung and pulmonary arteries after pneumonectomy. J. Appl. Physiol. 53:859-864.

28. Wilcox, B. R., G. F. Murray, M. Friedman, and R. L. Pimmel. 1979. The effects of early pneumonectomy on the remaining pulmonary parenchyma. Surgery (St. Louis). 86:294-300.

29. Crapo, J. D. and R. O. Crapo. 1983. Comparison of total lung diffusion capacity and the membrane component of diffusion capacity as determined by physiologic and morphometric techniques. Respir. Physiol. 51:183-194.

30. Crapo, J. D., R. O. Crapo, R. L. Jensen, R. R. Mercer, and E. R. Weibel. 1988. Evaluation of lung diffusing capacity by physiological and morphometric techniques [published erratum appears in J. Appl. Physiol. 1988, 65:following 2800]. J. Appl. Physiol. 64:2083-2091.

31. Grote, J. 1967. Die Sauerstoffediffusionscostanten im lungengewebe und wasser und ihre temperaturebhangikeit. Pfluegers Arch. Gesamte Physiol. Gesamte Physiol. Menschen Tiere. 295:245-254. 